Surface reactivity of tributyl thiophosphate

Effects of temperature and mechanical stress

\author{
Journal Article \\ Author(s): \\ Rossi, A.; Piras, F.M.; Kim, D.; Gellman, A.J.; Spencer, N.D. \\ Publication date: \\ 2006-09 \\ Permanent link: \\ https://doi.org/10.3929/ethz-b-000035895 \\ Rights / license: \\ In Copyright - Non-Commercial Use Permitted \\ Originally published in: \\ Tribology Letters 23(3), https://doi.org/10.1007/s11249-006-9051-6
}




\title{
Surface reactivity of tributyl thiophosphate: effects of temperature and mechanical stress
}

\author{
A. Rossi ${ }^{\mathrm{a}, \mathrm{b}}$, F.M. Piras ${ }^{\mathrm{a}, \mathrm{d}}$, D. Kim ${ }^{\mathrm{c}}$, A.J. Gellman ${ }^{\mathrm{c}}$ and N.D. Spencer ${ }^{\mathrm{a}, *}$ \\ ${ }^{a}$ Department of Materials, Laboratory for Surface Science and Technology, ETH Zurich, Wolfgang-Pauli-Strasse 10, CH-8093 Zurich, Switzerland \\ ${ }^{b}$ Dipartimento di Chimica Inorganica ed Analitica, Università degli Studi di Cagliari, Cittadella Universitaria di Monserrato, 09100, Cagliari, Italy \\ ${ }^{c}$ Department of Chemical Engineering, Carnegie Mellon University, 5000 Forbes Ave., Pittsburgh, PA 15213, USA \\ ${ }^{d}$ Department of Chemical and Biosystems Science and Technology, University of Siena, Via Aldo Moro 2, I-53100, Siena, Italy
}

Received 28 October 2005; accepted 6 March 2006; published online 30 September 2006

\begin{abstract}
The surface reactivity of tributyl thiophosphate on iron surfaces has been studied in situ by attenuated total reflection Fouriertransform infrared spectroscopy, X-ray photoelectron spectroscopy and temperature-programmed reaction and desorption spectroscopies. The results show that at temperatures lower than $373 \mathrm{~K}$ the molecule forms a physisorbed layer on the iron substrate. At $373 \mathrm{~K}$ a reaction takes place with the formation of an organic layer, together with iron polyphosphate and sulfate. At higher temperatures temperature-programmed desorption results suggest that the mechanism involves $\mathrm{P}-\mathrm{O}$ bond scission to yield butoxy groups. This could be preceded by $\mathrm{P}=\mathrm{S}$ bond scission to give tributyl phosphite, which then, in turn, undergoes $\mathrm{P}-\mathrm{O}$ bond scission to produce butoxy groups. The results obtained following tribological testing are in agreement with those of thermal tests: evidence of polyphosphate and sulfate formation is found.
\end{abstract}

KEY WORDS: tributyl thiophosphate, O,O,O,-tributyl phosphorothioate, ashless additives, lubrication, in situ tribology, surface chemistry, X-ray photoelectron spectroscopy (XPS), Auger electron spectroscopy (AES), temperature-programmed reaction spectroscopy (TPRS), attenuated total reflection Fourier transform infrared spectroscopy (ATR-FT-IR)

\section{Introduction}

Virtually all engine operating conditions, including those encountered in aerospace and automobile applications, require the use of lubricant additives, which modify friction and wear behavior, as well as other lubricant properties. Depending on the application, antiwear additives can be used either as solutes in oils or alternatively in the vapor phase, for systems operating in high-temperature $(>823 \mathrm{~K})$ environments. A wellstudied group of such antiwear additives consists of the organophosphate compounds; to this group belong tributyl phosphate (TBP), tricresyl phosphate (TCP) and trixylyl phosphate (TXP), as well as zinc dialkyl dithiophosphate (ZnDTP). A common feature of recent review papers $[1-3]$ reporting on different aspects of the research in this field, is that the surface reactivity, and therefore the antiwear properties of the lubricant additives, seem to be related to the formation of a surface film that not only differs in composition from the substrate but also is characterized by different mechanical properties. This has led to the application of a plethora of analytical techniques, ranging from pin-on-disk tests to the use of ex situ surface-analytical tools, such as X-ray photoelectron spectroscopy (XPS) [4-8], Auger electron spectroscopy (AES) $[9,10]$, X-ray absorption near-edge structure (XANES) [11-13], and time-of-flight

\footnotetext{
*To whom correspondence should be addressed. E-mail: Nicholas.Spencer@mat.ethz.ch
}

secondary-ion mass spectroscopy TOF-SIMS [14,15], which are used to characterize the film formed prior to the measurements. In situ (also called "in contact") methods, such as attenuated total reflection Fouriertransform infrared (ATR-FT-IR) [16,17] and Raman spectroscopies have also been applied $[18,19]$.

Many studies aimed at elucidating the reaction mechanism of TBP, TCP and related compounds have been performed using different surface analytical techniques [20,21], including temperature-programmed reaction spectroscopy (TPRS) - often in combination with AES, both on clean iron surfaces [22] and on oxidized iron [23], and more recently using a quartz crystal microbalance $[24,25]$. These studies provided evidence that in the cases of TBP and TCP the film formation takes place following breakage of the $\mathrm{C}-\mathrm{O}$ bond for the alkyl class and via $\mathrm{P}-\mathrm{O}$ bond scission in the case of the aryl class. Although studies with alkyl and aryl phosphites have been undertaken [26,27], to our knowledge no data are available on the corresponding sulfur-containing compounds. Some workers have studied the tribological properties of thiophosphate lubricant additives and the films formed by their reaction on iron surfaces. The interest in these compounds arises from their potential for use as ashless antiwear additives for possible replacement of zinc dialkyldithiophosphate (ZnDTP) [28-32]. Experimental evidence obtained by several research groups also shows that in addition to phosphorus, sulfur plays an important role in the 


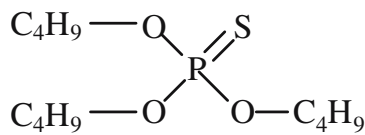

Scheme 1. Tributyl thiophosphate (TBT).

reaction mechanism of dithiophosphates as lubricant additives, although the reasons for this are not yet fully understood $[2,3]$.

In this work the reactivity of $o, o, o$,-tributyl phosphorothionate, also known as tributyl thiophosphate (TBT) (see scheme 1), with polycrystalline iron has been investigated at different temperatures by means of TPRS and AES and also under sliding contact boundary lubrication conditions with in situ ATRFT-IR and (ex situ) XPS. Our objective was to gain insight into the reaction mechanism of TBT, to compare it with that of TBP and to understand the origin of any observed differences. TPRS measurements have provided information on bond strengths with the surface and on desorption and decomposition mechanisms and kinetics. ATR-FT-IR spectroscopy has allowed identification of the functional groups present in the molecule, permitting the modifications occurring in the contact region to be followed on a molecular level and revealing whether their cause is thermal or an effect of mechanical stress. XPS has provided elemental identification as well as chemical-state information and quantitative analysis of the overlayer films.

\section{Experimental}

\subsection{Materials}

TBT was synthesized at Ciba Specialty Chemicals (Basel, Switzerland) from tributyl phosphite and an equimolar quantity of elemental sulfur (383-393 K, ca. $75 \mathrm{~min}$ ). Subsequently, it was purified by chromatography using a thin silica layer as a chromatographic plate and toluene and hexane as eluents [Information provided by Dr. H. Camenzind (Ciba Specialty Chemicals)]. Elemental analysis, Fourier transform infrared spectroscopy, mass spectroscopy and nuclear magnetic resonance ${ }^{1} \mathrm{H}$ and ${ }^{13} \mathrm{C}$ were performed, in order to check the purity of the sample. XPS data on a frozen sample deposited on mica were also collected.

Trapezoidal ATR elements of single crystal germanium with an angle of incidence of $45^{\circ}$, dimensions of $72 \times 10 \times 6 \mathrm{~mm}$ and 7 reflections have been used in this work for the infrared spectroscopy measurements. The iron coating of the crystals was performed by magnetron sputtering at the Paul Scherrer Institut (PSI, Villigen, Switzerland). Before each experiment, the thickness of the iron coating was checked by ellipsometry and found to be $12.0 \pm 0.3 \mathrm{~nm}$. The XPS analysis of the iron surface before testing indicated the presence of an iron

oxide film and its thickness was calculated from XPS data to be equal to $2.6 \pm 0.3 \mathrm{~nm}[33]$.

\subsection{Methods}

\subsubsection{In situ attenuated total reflection infrared} (ATR-FT-IR) tribometry

ATR FT-IR spectra were obtained with a Nicolet Magna-IR System 550 Fourier Transform Spectrometer equipped with an ATR assembly heatable to $200^{\circ} \mathrm{C}$ (Greasby Specac, Portmann Instruments AG, BielBenken, Switzerland). The spectra were measured using the experimental conditions listed in table 1. As a background spectrum, the single-beam spectrum of the iron-coated germanium ATR crystal was acquired before each experiment. The ATR FT-IR spectra presented in this work are reported after subtraction of the background spectrum, without any other correction.

Adsorption test at $353 \mathrm{~K}$ and $373 \mathrm{~K}$. Adsorption tests were performed by depositing the TBT directly onto the iron-coated germanium crystal of the attenuated total reflection infrared (ATR-FT-IR) spectrometer. ATR spectra were collected at $298 \mathrm{~K}$, both before thermal testing, and during thermal tests at 353 and $373 \mathrm{~K}$. Spectra were acquired at different times after cooling the crystal to room temperature: these alternating heating-cooling cycles were applied due to the increasing absorbance of the germanium with temperature [17].

Tribological tests at 353 and $373 \mathrm{~K}$. Sliding tests were performed using an in situ ATR-FT-IR tribometer under sliding conditions at high temperatures as previously described in detail [17]. The tribological experimental conditions used in this work (table 1) were chosen so as to ensure boundary lubrication conditions. Also, in this case, the ATR-FT-IR spectra have been measured after cooling the ATR tribometer down to room temperature after each heating cycle.

Following the tribological tests the samples were washed with cyclohexane (p.a. $\geq 99.5 \%$, Fluka), and transferred to the X-ray photoelectron spectrometer.

\subsubsection{X-ray photoelectron spectroscopy (XPS)}

XPS analyses were carried out using a PHI 5700 spectrometer equipped with a concentric hemispherical

Table 1.

Tribological experimental conditions.

Apparent contact area

Normal load

Apparent contact pressure

Average sliding velocity

Lubricant

Temperature

Relative humidity
$0.1 \mathrm{~mm}^{2}$

$7 \mathrm{~N}$

$60 \mathrm{MPa}$

$20 \mathrm{~mm} / \mathrm{min}$

Tributyl thiophosphate 298, 353, $373 \mathrm{~K}$

$50 \%$ 
analyzer in the standard configuration (Physical Electronics, Eden Prairie, MN, USA). The vacuum system consists of a turbo-molecular pump, ion pump, and a titanium sublimation pump. The base pressure before the analysis was better than $10^{-7} \mathrm{~Pa}$. The X-ray source was $\mathrm{Al} K_{\alpha}(1486.6 \mathrm{eV})$, run at $300 \mathrm{~W}$. The incident angle was $54.7^{\circ}$ and the emission angle was $45^{\circ}$ with respect to the sample surface normal. All the spectra were obtained in digital mode. A constant pass energy of $23.50 \mathrm{eV}$ through the hemispheres of the electron analyzer operated in the Fixed Analyzer Transmission (FAT) mode was used for the narrow-scan; the wide-scan spectra were acquired with a pass energy of $187.85 \mathrm{eV}$. The instrument was operated in minimum-area mode and the aperture was $0.4 \mathrm{~mm}$ diameter. The instrument was calibrated using the inert-gas-ion-sputter-cleaned SCAA90 reference materials $\mathrm{Cu}, \mathrm{Ag}$ and $\mathrm{Au}$ [34]. The accuracy of the binding energy values was found to be $\pm 0.05 \mathrm{eV}$. The binding-energy values reported in this work are the mean values over at least three independent measurements. The standard deviation is also reported.

Sample charging was corrected by referring all binding energies to the carbon 1s signal at $285.0 \mathrm{eV}$. The spectra were resolved into their Gaussian-Lorentzian components after background subtraction using CASA XPS software (V2.0, CASA Software Ltd, UK).

The atomic concentration of element $j$ was calculated as:

$$
X_{j}=\frac{I_{i j} / S_{i j}}{\sum_{j}\left(I_{i j} / S_{i j}\right)},
$$

where $I_{i j}$ is the area of the peak $i$ of the element $j$, and $S_{i j}$ is the sensitivity factor. The sensitivity factors were calculated from the Scofield photoionization cross sections [35], the inelastic mean free path corrected for the emission angle, and the transmission function of the analyzer, as described in Ref. [36], assuming the sample to be homogeneous. The inelastic mean free path, i.e. the mean distance that particles with a given kinetic energy (KE) travel between inelastic collisions in a substance, corrected for the emission angle $(\vartheta)$ was calculated as:

$$
\Lambda_{i j}=\frac{A}{\mathrm{KE}}+B \times \sqrt{\mathrm{KE}} \times \cos \vartheta,
$$

where the values of $A$ and $B$ are 31 and 0.087 , respectively, and $\Lambda_{i j}$ is in $\mathrm{nm}$. These values are valid for organic compounds, according to [37], and they have been used to calculate the sensitivity factors for pure compounds measured frozen on mica (table 2).

\subsubsection{TPRS}

The temperature-programmed-reaction spectra and the Auger electron spectra were obtained in a stainlesssteel ultra high vacuum (UHV) chamber with a base pressure of $<10^{-7} \mathrm{~Pa}$. The chamber is equipped with an ion-sputtering gun for surface cleaning by argon ion $\left(\mathrm{Ar}^{+}\right)$bombardment, a quadrupole mass spectrometer (QMS), and a cylindrical mirror analyzer (CMA) for AES. Standard leak valves were used to introduce high vapor pressure compounds such as 1-butene, 1-butanol, and butanal into the UHV chamber for adsorption on the Fe surface. A high-mass doser was used for the adsorption of extremely low vapor pressure compounds, such as TBP or TBT. This doser consists of a glass sample vial at the end of a long $(\sim 40 \times 1.25 \mathrm{~cm}$ diameter) collimating tube.

The $\mathrm{Fe}$ sample consisted of polycrystalline $\mathrm{Fe}$ $(99.99+\%)$ foil, and was spot-welded to tantalum wires that were in mechanical contact with a liquid nitrogen reservoir through a sample holder. The sample could be cooled to $110 \mathrm{~K}$ or heated resistively to higher than $1000 \mathrm{~K}$ with the temperature measured by a K-type thermocouple spot-welded to the back of the Fe sample. Initial cleaning of the $\mathrm{Fe}$ sample was achieved by repeated cycles of $\mathrm{Ar}^{+}$ion bombardment followed by thermal treatment to $800 \mathrm{~K}$. Routine sample prepara-

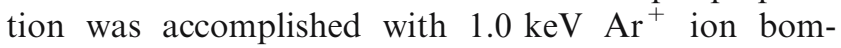
bardment for $50 \mathrm{~min}$ at $200 \mathrm{~K}$ followed by thermal treatment at $800 \mathrm{~K}$ for $1 \mathrm{~min}$. TBT was kept in the glass vial of the high-mass doser and the dosing tube was moved into the chamber to position the end of the tube approximately $5 \mathrm{~mm}$ from the Fe surface.

The TPRS spectra were obtained by first adsorbing a monolayer of the TBT on the cleaned Fe surface at $110 \mathrm{~K}$. At $110 \mathrm{~K}$ the TBT will adsorb molecularly on the Fe surface without subsequently desorbing into the vacuum. The surface was then positioned in front of the QMS and heated at a constant rate of $1 \mathrm{~K} / \mathrm{s}$. The mass spectrometer was used to monitor the signals of ionization fragments generated at several different $\mathrm{m} / \mathrm{q}$ ratios by the desorbing reaction products.

\subsubsection{Auger electron spectroscopy}

The Auger electron spectra were obtained from the Fe surface before and after TPRS experiments using a single-pass, cylindrical-mirror analyzer (Varian Inst.). The primary electron beam was incident on the Fe surface along its normal with a beam energy of $3 \mathrm{keV}$. The modulation voltage used to record the spectra was $3 \mathrm{eV}$. All spectra were obtained with the sample held at $110 \mathrm{~K}$.

\section{Results}

TBT has been characterized by means of transmission FT-IR, ATR, and XP spectroscopies. The results obtained from in situ ATR thermal and tribological tests in the presence of pure TBT, and from the subsequent ex situ XPS analysis, are reported in the following paragraphs; finally, the results obtained with the temperature programmed reaction spectroscopy are described. 
Table 2.

IR frequencies $\left(\mathrm{cm}^{-1}\right)$ and functional group assignments for the IR spectra of TBT.

\begin{tabular}{|c|c|c|c|}
\hline Transmission & ATR (Ge uncoated) & $\operatorname{ATR}(\mathrm{Ge} / \mathrm{Fe})$ & Functional group \\
\hline \multicolumn{4}{|l|}{ Tributyl thiophosphate } \\
\hline $2960,2935,2896(\mathrm{sh})$ & 2960, 2935, $2896(\mathrm{sh})$ & 2956,2932 & $v_{\mathrm{as}} \mathrm{CH}_{3}, v_{\mathrm{as}} \mathrm{CH}_{2}$ \\
\hline $2875,2846(\mathrm{sh})$ & $2875,2844(\mathrm{sh})$ & 2872 & $v_{\mathrm{s}} \mathrm{CH}_{3}, v_{\mathrm{s}} \mathrm{CH}_{2}$ \\
\hline $1465 \mathrm{~m}, 1460$ (sh), $1433 \mathrm{w}$ & $1466 \mathrm{~m}, 1460(\mathrm{sh}), 1433 \mathrm{w}$ & $1458 \mathrm{~m}, 1431 \mathrm{w}$ & $\delta_{\mathrm{as}} \mathrm{CH}_{3}, \delta \mathrm{CH}_{2}$ \\
\hline $1382 \mathrm{w}$ & $1381 \mathrm{w}$ & $1379 \mathrm{w}$ & $\delta_{\mathrm{s}} \mathrm{CH}_{3}$ \\
\hline $1264 \mathrm{vw}, 1234 \mathrm{w}$ & $1264 \mathrm{vw}, 1234 \mathrm{w}$ & $1232 \mathrm{w}$ & \\
\hline $1150 \mathrm{w}, 1120 \mathrm{w}$ & $1149 \mathrm{w}, 1120 \mathrm{w}$ & $1147 \mathrm{w}, 1120 \mathrm{w}$ & $v \mathrm{C}-\mathrm{O}-(\mathrm{P})$ \\
\hline 1059 s, 1024 vs, 987 s & $1058 \mathrm{~s}, 1021 \mathrm{vs}, 986 \mathrm{~s}$ & $1056 \mathrm{~m}, 1016 \mathrm{~s}$ & \\
\hline 980 (sh), 958 (sh) & $977(\mathrm{sh}), 958(\mathrm{sh})$ & 973 (sh), 956 (sh) & $v \mathrm{P}-\mathrm{O}-(\mathrm{C})$ \\
\hline $904 \mathrm{~m}$ & $903 \mathrm{~m}$ & $896 \mathrm{~m}$ broad & \\
\hline $851(\mathrm{sh}), 836 \mathrm{~m}, 809 \mathrm{~m}$ broad & 851 (sh), $835 \mathrm{~m}, 809 \mathrm{~m}$ broad & & $\mathrm{P}=\mathrm{S}(\mathrm{I})$ \\
\hline $737 \mathrm{w} / \mathrm{m}$ & $737 \mathrm{w} / \mathrm{m}$ & & $\rho \mathrm{CH}_{2}$ \\
\hline $648(\mathrm{sh}), 628 \mathrm{w} / \mathrm{m}$ & & & $\mathrm{P}=\mathrm{S}(\mathrm{II})$ \\
\hline
\end{tabular}

$v_{\mathrm{s}}=$ symmetric stretching. $v_{\mathrm{as}}=$ asymmetric stretching. $\delta_{\mathrm{as}}=$ asymmetric bending. $\delta_{\mathrm{s}}=$ symmetric bending. $\rho=$ rocking. sh $=$ shoulder. $\mathrm{w}=$ weak. $\mathrm{m}=$ medium

\subsection{Characterization of tributyl thiophosphate}

\subsubsection{Transmission FT-IR and ATR spectra}

In figure 1, the transmission FT-IR and ATR spectra of TBT are reported. The ATR spectra have been measured using an uncoated and an iron-coated $(10 \mathrm{~nm})$ germanium ATR crystal. The IR frequencies and the assigned functional groups for the transmission and the
ATR spectra of the TBT, are reported in Table 2. The assigned functional groups are in agreement with the literature [38-43]. Three spectral regions can be distinguished in the TBT spectra (figure 1):

(i) the region at high wavenumbers $\left(3000-2800 \mathrm{~cm}^{-1}\right)$ - symmetric and asymmetric stretching vibrations of the $\mathrm{CH}_{3}, \mathrm{CH}_{2}$ and $\mathrm{CH}$ groups;
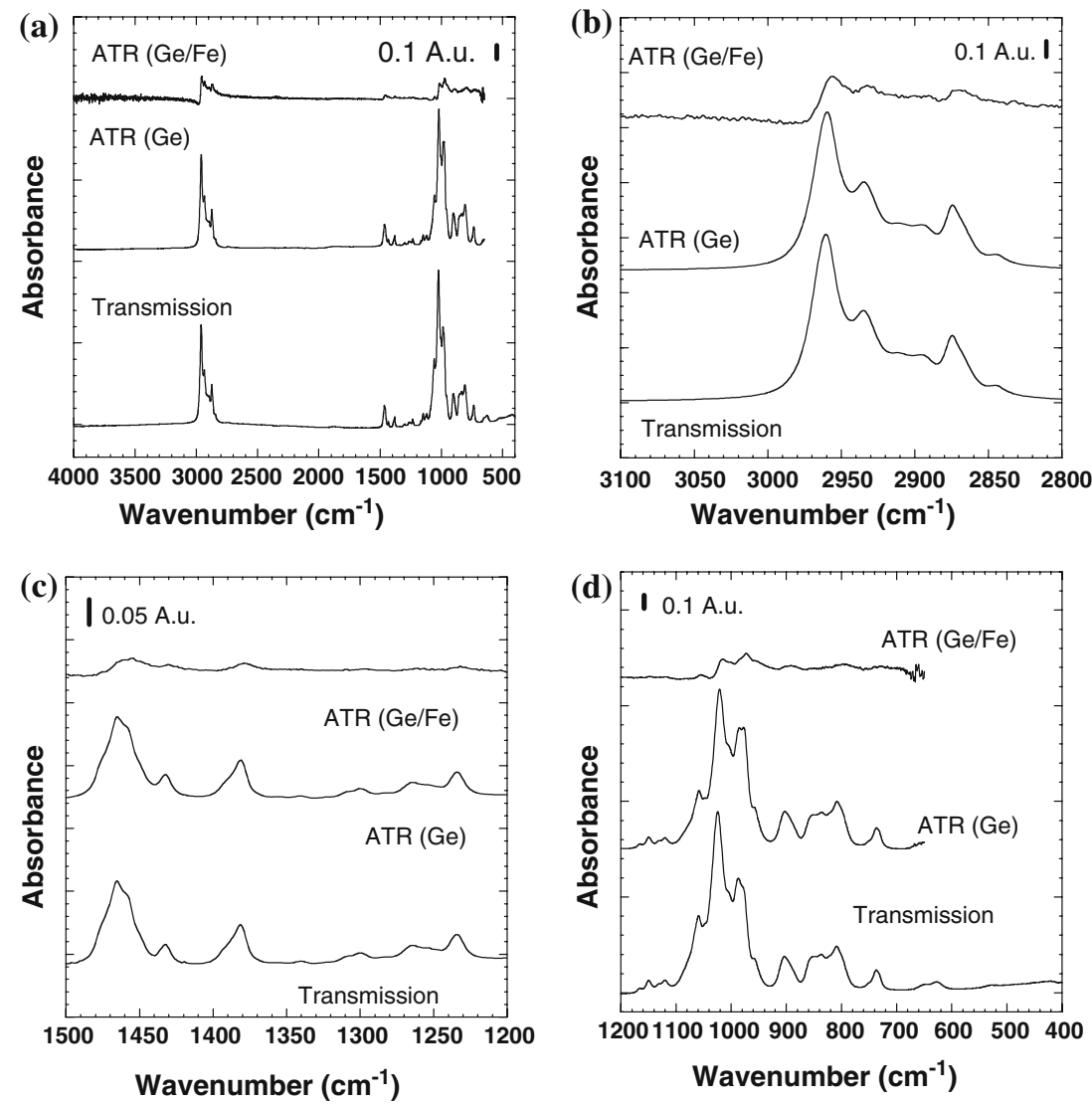

Figure 1. Transmission FT-IR and ATR spectra of TBT. The whole spectral region (a) and three enlarged regions (b-d) are shown. The ATR spectra have been acquired using germanium ATR crystals, uncoated and coated with iron. ATR and baseline corrections have been applied to the ATR spectra. 
(ii) the region between 1500 and $1200 \mathrm{~cm}^{-1}$ - bending vibrations of $\mathrm{CH}_{3}$ and $\mathrm{CH}_{2}$ groups;

(iii) and the fingerprint region $\left(1200-400 \mathrm{~cm}^{-1}\right)$.

In the transmission spectrum, the very intense $v \mathrm{P}-\mathrm{O}-(\mathrm{C})$ band falls at $1024 \mathrm{~cm}^{-1}$, but it is shifted to 1021 and $1020 \mathrm{~cm}^{-1}$ in the ATR spectra collected on germanium and iron-coated germanium, respectively. The characteristic $\mathrm{P}=\mathrm{S}$ (I) and $\mathrm{P}=\mathrm{S}$ (II) absorption bands are detected at 836 and $628 \mathrm{~cm}^{-1}$, respectively. The IR bands shown in the ATR $(\mathrm{Ge} / \mathrm{Fe})$ spectrum are skewed towards low wavenumbers, and the relative intensities of the $v \mathrm{P}-\mathrm{O}-(\mathrm{C})$ signals are different with respect to the transmission and the ATR (Ge uncoated) spectrum.

\subsection{2. $X P S$}

In figure 2, the wide scan and the detailed XPS spectra of C1s, O1s, P2p and S2p of TBT frozen on mica, an inert substrate, are reported. The $\mathrm{C} 1 \mathrm{~s}$ signal contains two components at 285.0 and $286.7 \mathrm{eV}$, assigned to the carbon of the aliphatic chains of the butyl groups and to carbon bonded to oxygen (C-O-P) [45], respectively. The $\mathrm{O} 1 \mathrm{~s}$ of the $\mathrm{C}-\mathrm{O}-\mathrm{P}$ group shows a single peak with a maximum at $533.0 \mathrm{eV}$. The binding energy of the $\mathrm{P} 2 \mathrm{p}_{3 / 2}$
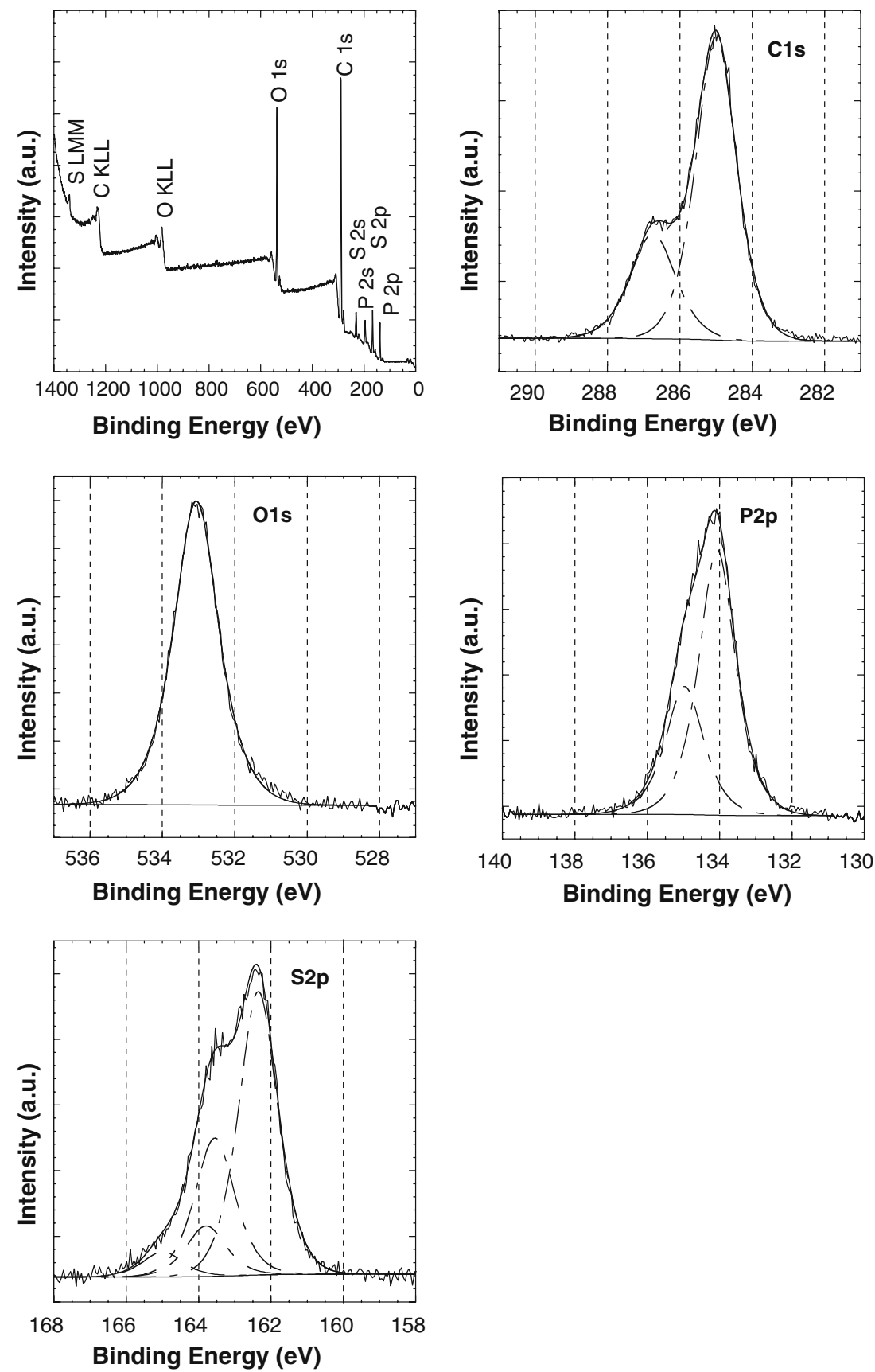

Figure 2. Survey and high-resolution XPS spectra of C1s, O1s, P2p and S2p of TBT frozen on mica. 
Table 3.

XPS binding energies (B.E.), full widths at half-maximum height (FWHM) and experimental results of quantitative analysis of TBT (frozen on mica).

\begin{tabular}{|c|c|c|c|c|c|c|}
\hline & C1s (1) & Cls (2) & O1s & $\mathrm{P} 2 \mathrm{p}_{3 / 2}$ & $\mathrm{~S} 2 \mathrm{p}_{3 / 2}$ & $\mathrm{~S} 2 \mathrm{p}_{3 / 2}(2)$ \\
\hline Assignment & C-H & $\mathrm{C}-\mathrm{O}-\mathrm{P}$ & $\mathrm{C}-\mathrm{O}-\mathrm{P}$ & $(-\mathrm{CO})_{3}-\mathbf{P}=\mathrm{S}$ & $\mathrm{P}=\mathrm{S}$ & $\mathbf{S}^{0}$ \\
\hline B.E. $(\mathrm{eV})$ & 285.0 & 286.6 & 533.0 & 134.1 & 162.3 & 163.8 \\
\hline FWHM & 1.5 & 1.5 & 1.5 & 1.3 & 1.4 & 1.4 \\
\hline Area ratio & \multicolumn{2}{|c|}{$3: 1$} & & & \multicolumn{2}{|c|}{$6: 1$} \\
\hline Atomic $\%$ calc. & \multicolumn{2}{|c|}{$\begin{array}{l}70.6 \% \\
71.0 \%\end{array}$} & $17.6 \%$ & $5.9 \%$ & $5.9 \%$ & - \\
\hline Atomic $\%$ exp. & \multicolumn{2}{|c|}{$71.0 \%$} & $16.4 \%$ & $6.5 \%$ & $6.1 \%$ & - \\
\hline
\end{tabular}

component has been found at $134.1 \mathrm{eV}$ : the P2p spectrum is a convolution of the $\mathrm{P} 2 \mathrm{p}_{3 / 2}$ and $\mathrm{P} 2 \mathrm{p}_{1 / 2}$ components that were resolved keeping their difference and their branching ratio equal to 0.95 and $0.5 \mathrm{eV}$, respectively. The S2p is asymmetric because of the spin-orbit splitting and it has been fitted using two GaussianLorentzian functions at a fixed separation of $1.2 \mathrm{eV}$ and with an intensity ratio of 0.5 . The S2p signal has been fitted with two doublets, having the maxima of their S2 $\mathrm{p}_{3 / 2}$ components at 162.3 and $163.8 \mathrm{eV}$, respectively. The first component is assigned to the sulfur in the $\mathrm{P}=\mathrm{S}$ group whereas the second component (only few percent of the intensity of the main peak) can be assigned to traces of elemental sulfur used for the chemical synthesis of the TBT. Table 3 reports the results of quantitative analysis of the elemental composition of the TBT: good agreement is found between the calculated and the experimental atomic concentration values.

\subsection{Adsorption tests at different temperatures}

\subsubsection{ATR}

ATR spectra of TBT have been measured using germanium ATR crystals coated with iron, immediately after the deposition of TBT on the crystal and during the adsorption tests at 353 and $373 \mathrm{~K}$. The TBT ATR spectrum collected at $353 \mathrm{~K}(0 \mathrm{~h})$ on an iron-coated germanium ATR crystal shows the expected characteristic IR absorption bands (see spectrum ATR $(\mathrm{Ge} / \mathrm{Fe})$ in figure 1 and column 3 in table 2). At $353 \mathrm{~K}$, the acquired TBT ATR spectra (not shown here) do not show changes even after heating for periods of $38 \mathrm{~h}$, whereas significant changes in the TBT ATR spectrum have been observed after $20 \mathrm{~h}$ of heating at $373 \mathrm{~K}$ (figure 3). The TBT reacted with the iron film, which was partially removed, leading to a very intense absorption band having a maximum at $1023 \mathrm{~cm}^{-1}$. Two bands, one between 1350 and $1190 \mathrm{~cm}^{-1}$ and the other between 1187 and $1138 \mathrm{~cm}^{-1}$, were detected after $20 \mathrm{~h}$ of heating at $373 \mathrm{~K}$.

\subsubsection{XPS}

Ex situ XPS analysis of the iron-coated germanium ATR crystal was performed after the in situ ATR thermal test at $373 \mathrm{~K}$, in which changes in the TBT ATR spectrum were detected. In figure 4, the detailed XPS spectra of C1s,
O1s, P2p, S2p, and Fe2p $3 / 2$ of TBT on an iron-coated germanium ATR crystal, after heating at $373 \mathrm{~K}$ for $20 \mathrm{~h}$, are reported. Table 4 lists the binding energy values of the peak maxima after resolving the multicomponent signals using model Gaussian-Lorentzian curves with a FWHM at the maximum height and $\mathrm{G} / \mathrm{L}$ ratio taken equal to those obtained for the pure TBT frozen on mica. The intensity ratios within the different components of the same element are also shown. These data are reported together with
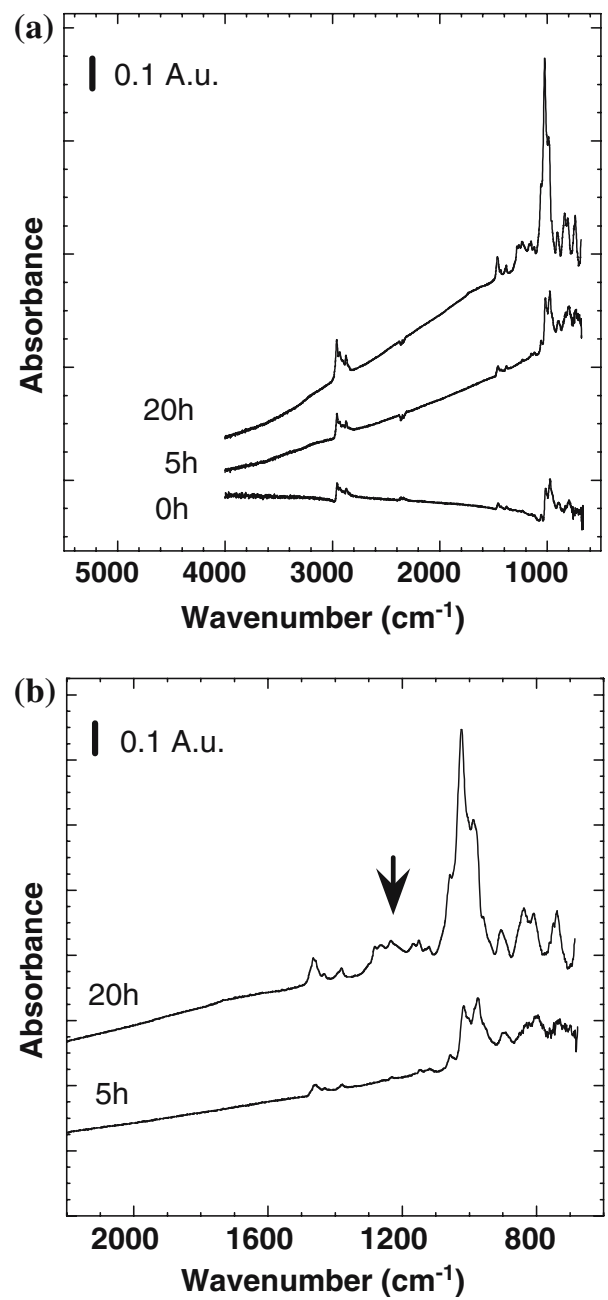

Figure 3. TBT ATR spectra collected during a thermal test at $373 \mathrm{~K}$, on a germanium ATR crystal coated with iron. In (a) and (b) are shown the whole spectral region and the fingerprint region, respectively. 

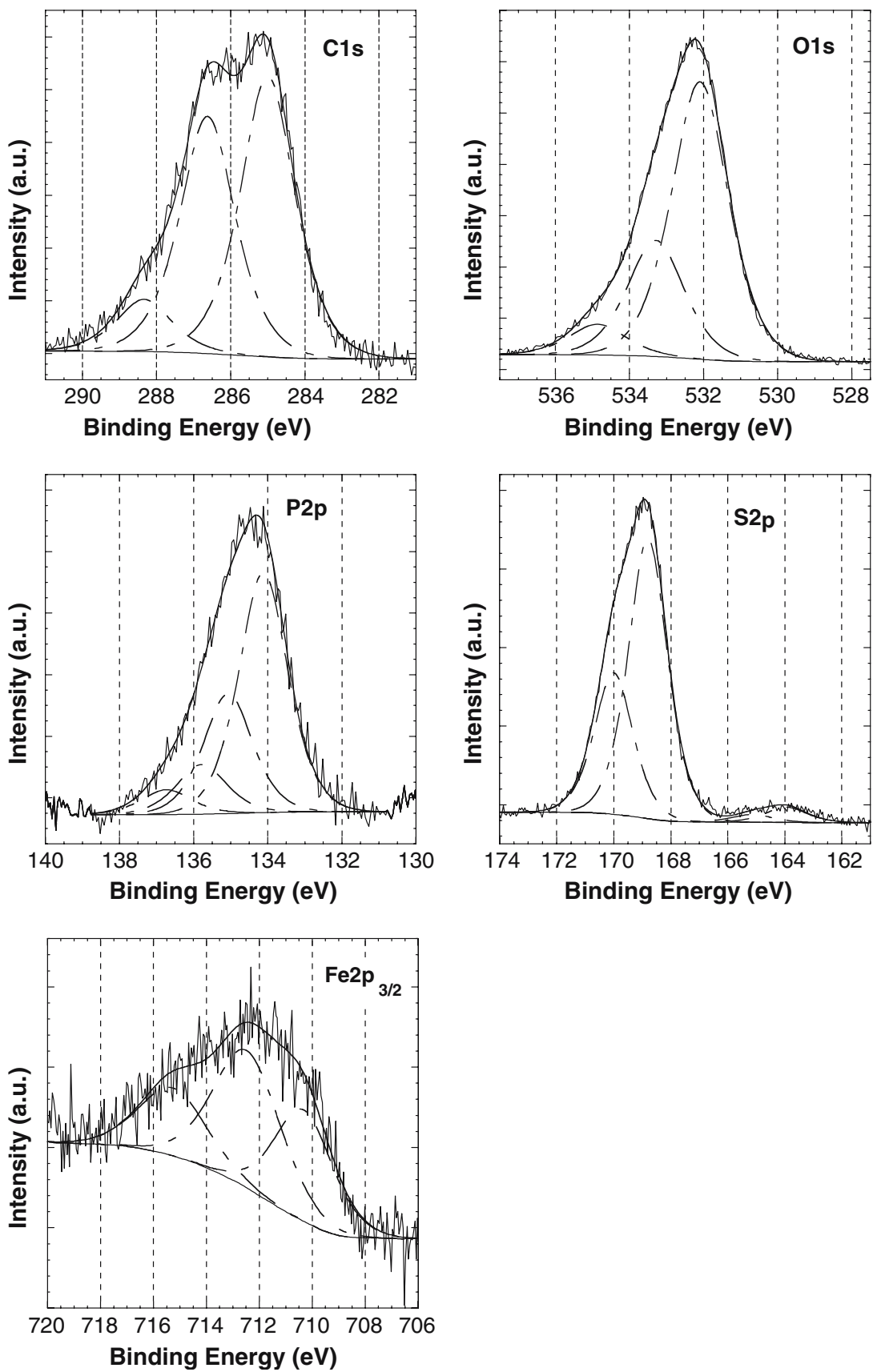

Figure 4. High-resolution XPS spectra of C1s, O1s, P2p, S2p and Fe2p $p_{3 / 2}$ of TBT on an Fe-coated Ge ATR crystal after thermal treatment at $373 \mathrm{~K}$ for $20 \mathrm{~h}$.

those obtained after the tribological test performed at the same temperature. A reaction with iron occurs following heating at $373 \mathrm{~K}$ : iron reacts with the TBT but the surface is not homogeneous, in some places the iron coating is removed whereas in other regions a film covers the surface. The latter fact can be seen by looking at the XP iron signal: the native oxide layer, under the thermal film, contributes to the XP Fe2p signal with the component at $710.5 \mathrm{eV}$. The other two components at 712.3 and at $714.8 \mathrm{eV}$ might be assigned to iron sulfate $\left(\mathrm{FeSO}_{4}\right)$ plus iron poly(thio)phosphate, and to $\mathrm{Fe}_{2}\left(\mathrm{SO}_{4}\right)_{3}$, respectively. The sulfur exhibits two components: a weak one at $164.0 \mathrm{eV}$, possibly due to an intermediate sulfur species, and the most intense one at $168.8 \mathrm{eV}$. This second component can be assigned to the iron sulfate compounds. Also the phosphorus spectrum presents a new signal with a peak maximum at $135.7 \mathrm{eV}$. The $\mathrm{C} 1 \mathrm{~s}$ spectrum with the signals at 286.6 and $288.0 \mathrm{eV}$ suggests the formation of organic derivatives that contain oxygen functionalities.

\subsection{Tribological tests}

\subsubsection{ATR tribometry}

Sliding tests in the presence of TBT have been carried out at 353 and $373 \mathrm{~K}$. The ATR spectra of TBT acquired 

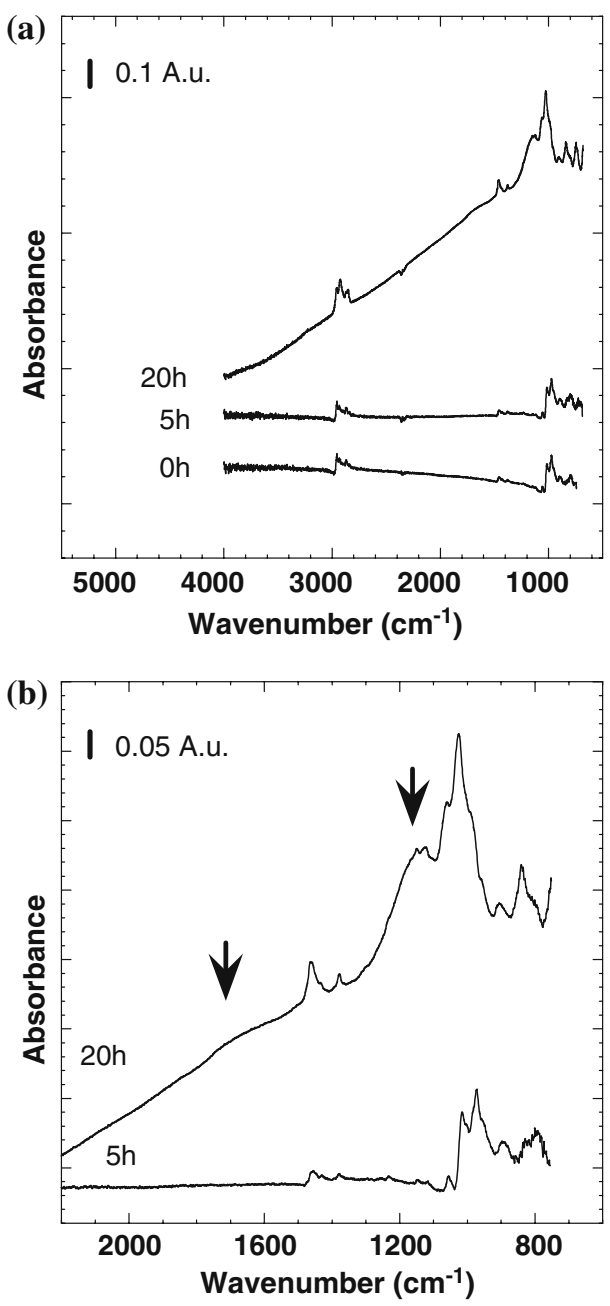

Figure 5. ATR spectra of TBT ATR spectra acquired during a tribotest at $373 \mathrm{~K}$ on a germanium crystal coated with iron. In (a) and (b) are shown the whole spectral region and the fingerprint region, respectively.

during tribological stress at ambient temperature and at $353 \mathrm{~K}$, using an iron-coated germanium ATR crystal do not show significant changes during sliding for periods of up to $38 \mathrm{~h}$. After $20 \mathrm{~h}$ of sliding at $373 \mathrm{~K}$, significant changes have been detected in the TBT ATR spectrum (figure 5). A very intense absorption band having a maximum at $1023 \mathrm{~cm}^{-1}$ and a new broad band between 1300 and $1100 \mathrm{~cm}^{-1}$, with a maximum at ca. $1130 \mathrm{~cm}^{-1}$, are detected. A very weak and broad band appears between 1600 and $1750 \mathrm{~cm}^{-1}$. This band may be assigned to the stretching vibration of a carbonyl group [39].

\subsubsection{XPS spectra}

The iron-coated germanium ATR crystal has been analyzed by XPS after in situ ATR tribological tests performed at $373 \mathrm{~K}$. The surface was not homogeneous: in some points the coating appeared to be removed. The spectra shown here were collected in the contact region where the tribological film was clearly visible and the survey spectrum did not show the presence of the germanium signal due to the substrate. In figure 6 , the high-resolution XPS spectra of C1s, O1s, P2p, S2p and $\mathrm{Fe} 2 \mathrm{p}_{3 / 2}$ are displayed. Table 4 summarizes binding energy values and intensity ratios between the different components. The reaction during tribological testing yields a film with signals of $\mathrm{C} 1 \mathrm{~s}, \mathrm{O} 1 \mathrm{~s}, \mathrm{P} 2 \mathrm{p}_{3 / 2}$ and $\mathrm{Fe} 2 \mathrm{p}_{3 / 2}$ having the same energy within the experimental uncertainty $( \pm 0.2 \mathrm{eV})$ but with quite different intensity ratios. Differences are observed in the S2p signal, which besides the peak at $168.8 \mathrm{eV}$ (assigned to a sulfate group) shows a second peak at higher binding energies $(170.5 \mathrm{eV})$. This peak might be assigned to the presence of $\left(\mathrm{CH}_{3} \mathrm{O}\right)_{2} \mathrm{SO}$ (see below).

\subsection{Temperature-programmed reaction spectra}

Figure 7 shows the temperature-programmed reaction spectra (TPRS) of TBT on Fe. One monolayer of TBT was adsorbed on the Fe surface at $120 \mathrm{~K}$. The surface was then heated at $1 \mathrm{~K} / \mathrm{s}$ while using the mass spectrometer to measure the desorption rates of its decomposition products during heating. One monolayer of TBP was then adsorbed on the Fe surface and its decomposition products were examined during heating. Figure 8 shows the TPRS of TBP on Fe. The primary products of TBP and TBT decomposition are butene, butanal, and butanol. Table 5 shows the TPRS peak areas for the desorption products of TBP and TBT on $\mathrm{Fe}$ and the ionization patterns of butene, butanal, and butanol collected in our apparatus. The TPR spectra suggest that the decomposition of the TBT leads to the formation of more oxygenated products than the decomposition of TBP. Auger spectra of the Fe surface following the thermal decomposition of TBP and TBT by heating to $800 \mathrm{~K}$ are shown in figure 9. Decomposition of TBP results in the deposition of phosphorus onto the surface, while TBT also deposits sulfur.

\section{Discussion}

\subsection{Composition of the thermal film}

The ATR-FT-IR spectra collected at $353 \mathrm{~K}$ remain unchanged over time when compared with the transmission spectra and with those collected on both uncoated and iron-coated germanium crystals. These results suggest that at low temperatures the interaction at the molecular level between TBT and the iron substrate, even in the presence of 2.6-nm oxy-hydroxide layer formed in contact with the air, is weak. The monolayer is probably only physisorbed on the substrate. After heating at $373 \mathrm{~K}$ a reaction occurs which even causes the partial removal of the iron coating from the ATR germanium crystal surface. The two bands between 1350 and $1190 \mathrm{~cm}^{-1}$ and 1187 and $1138 \mathrm{~cm}^{-1}$ might be assigned to the stretching vibrations of the sulfate group in organic sulfate that generally appear in 

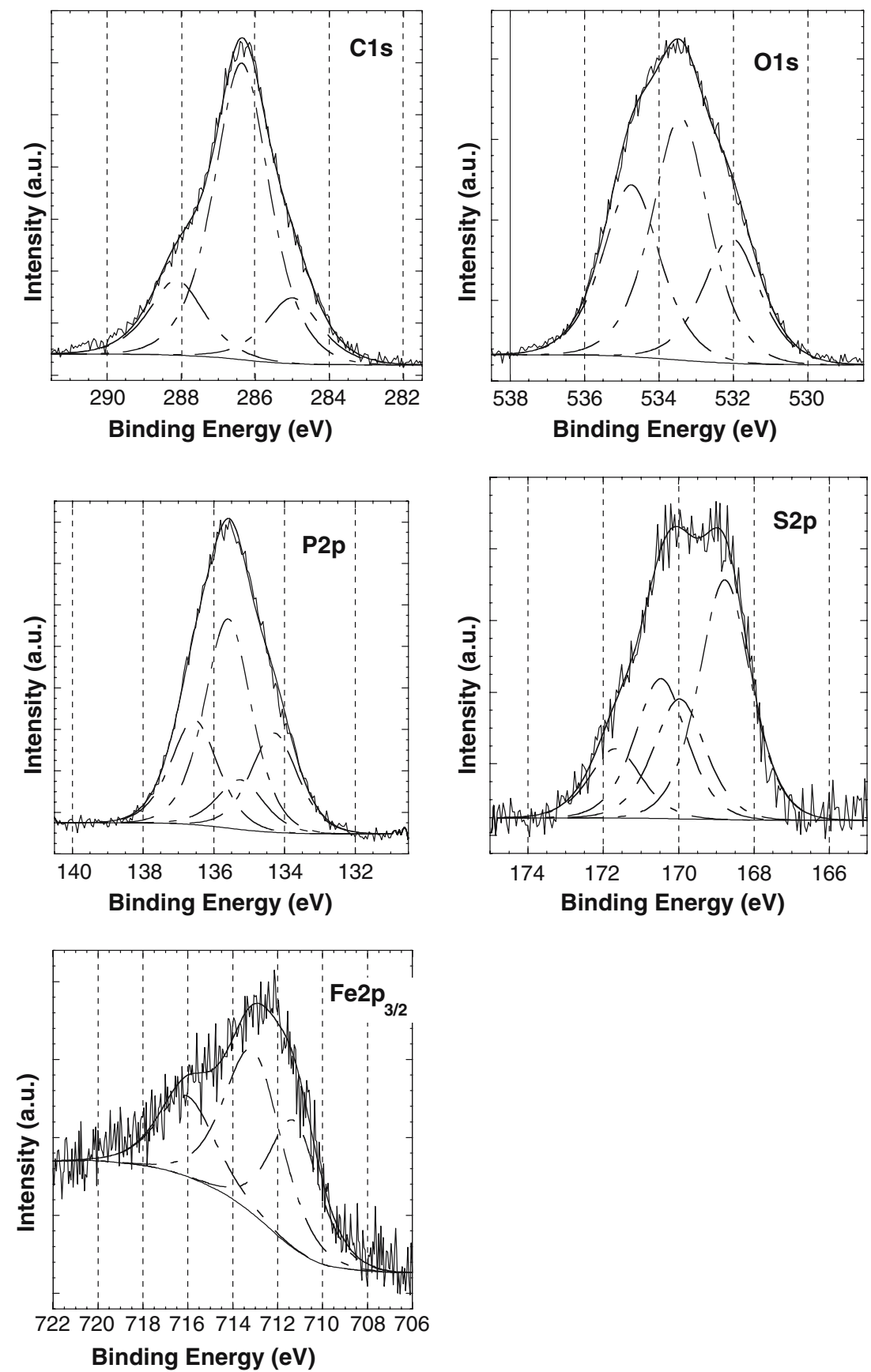

Figure 6. High-resolution XPS spectra of C1s, O1s, P2p, S2p and Fe2p $p_{3 / 2}$ of TBT on an Fe-coated Ge ATR crystal after tribological testing at $373 \mathrm{~K}$.

Table 4.

Binding energy values $( \pm 0.1 \mathrm{eV})$ and area ratios obtained after curve-fitting of the photoelectron signals.

\begin{tabular}{|c|c|c|c|c|c|c|c|c|c|c|c|c|}
\hline & C1s (1) & C1s (2) & C1s (3) & O1s (1) & Ols (2) & O1s (3) & $\mathrm{S} 2 \mathrm{p}_{3 / 2}(1)$ & $\mathrm{S} 2 \mathrm{p}_{3 / 2}(2)$ & $\mathrm{S} 2 \mathrm{p}_{3 / 2}(3)$ & $\mathrm{P} 2 \mathrm{p}_{3 / 2}(1)$ & $\mathrm{P} 2 \mathrm{p}_{3 / 2}(2)$ & $\mathrm{Fe} 2 \mathrm{p}_{3 / 2}$ \\
\hline $\begin{array}{l}\text { Frozen on mica } \\
\text { Area ratio }\end{array}$ & 285.0 & $\begin{array}{l}286.6 \\
3: 1\end{array}$ & - & - & 533.0 & - & 162.3 & $\begin{array}{l}163.8 \\
6: 1\end{array}$ & - & 134.1 & - & - \\
\hline $\begin{array}{l}\text { Deposited on iron } \\
\text { and heated at } 373 \mathrm{~K}\end{array}$ & 285.0 & 286.6 & 288.3 & 532.1 & 533.3 & 534.8 & - & 164.0 & 168.8 & 134.1 & 135.7 & 712.5 \\
\hline Area ratio & & $5: 4: 1$ & & & $8: 2: 1$ & & & $1: 17$ & & & $5: 1$ & \\
\hline Sliding test at $373 \mathrm{~K}$ & 285.0 & 286.4 & 288.1 & 532.2 & 533.4 & 534.8 & - & - & $\begin{array}{l}168.8 \\
170.5\end{array}$ & 134.3 & 135.6 & 712.5 \\
\hline Area ratio & & $1: 4: 1$ & & & $2: 3: 2$ & & & $2: 1$ & & & $1: 2$ & \\
\hline
\end{tabular}

These values refer to spectra shown in figures 2,4 and 6 . 


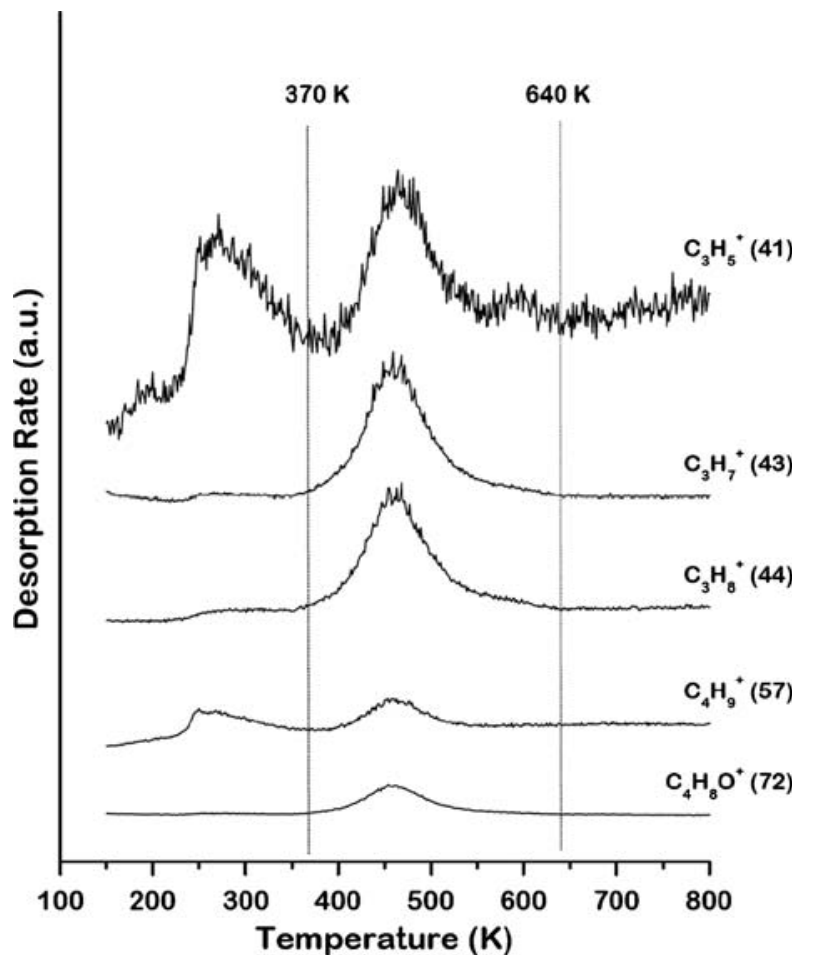

Figure 7. TPR spectra of TBT decomposition on Fe. TBT was adsorbed at $110 \mathrm{~K}$ and then heated at $1 \mathrm{~K} / \mathrm{s}$ while monitoring the signals of desorbing product ionization fragments. The products desorbing in the temperature range $370-640 \mathrm{~K}$ are predominantly butanal.

the ranges $1415-1180 \mathrm{~cm}^{-1}$ and $1200-1185 \mathrm{~cm}^{-1}$ [43,44]. The very intense peak at $1023 \mathrm{~cm}^{-1}$ that is due to $v \mathrm{P}-\mathrm{O}-$ $\mathrm{C}$ might also suggest the presence of an organic phosphate. The fact that the $\mathrm{P}-\mathrm{O}-\mathrm{P}$ signal found at $\sim 916 \mathrm{~cm}^{-1}$ is not clearly detected might be due to the convolution of the different signals in this region.

The XPS results for thermally treated TBT on iron indicate that the component of the $\mathrm{C} 1 \mathrm{~s}$ signal at $286.6 \mathrm{eV}$ is more intense than in pure TBT (figure 4 and table 4). This signal may contain contributions due to butanal and butanol that may be forming, as indicated by the TPR spectra (figure 7 and table 5). The O1s spectrum can be modeled using three GaussianLorentzian functions but their precise assignment is made difficult because of the simultaneous presence of contributions due to the native iron oxide layer, mainly to the peak at $532.1 \pm 0.1 \mathrm{eV}$, and to the peaks due to

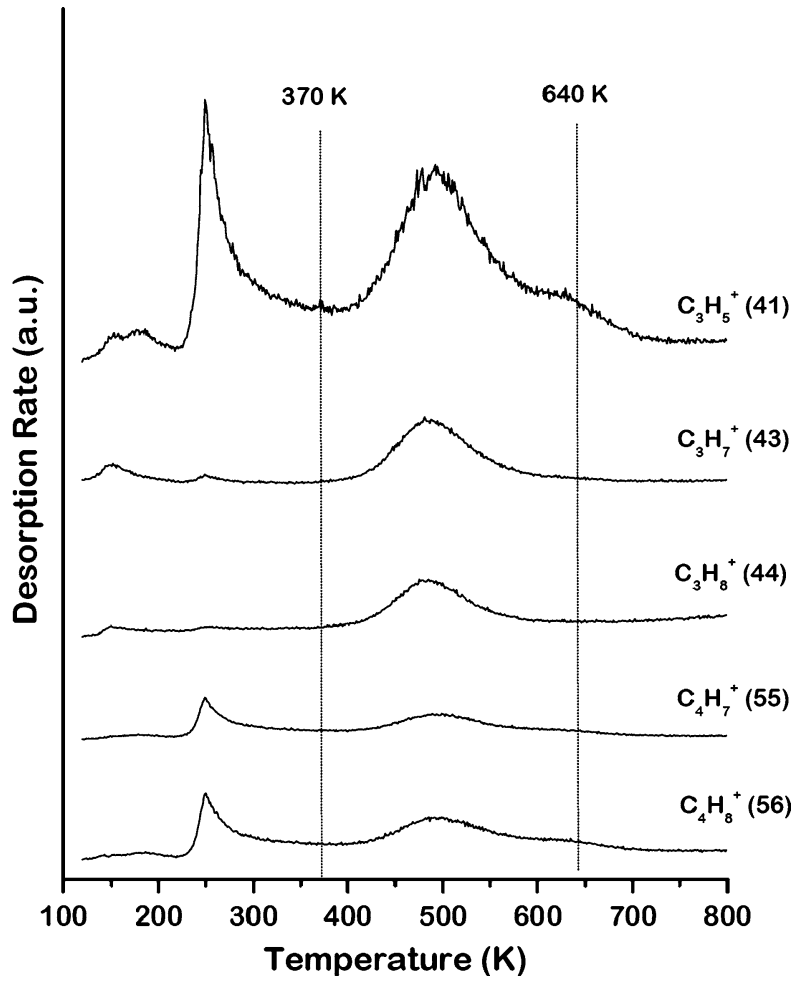

Figure 8. TPR spectra of TBP decomposition on Fe. TBP was adsorbed at $110 \mathrm{~K}$ and then heated at $1 \mathrm{~K} / \mathrm{s}$ while monitoring the signals of desorbing product ionization fragments. The products desorbing in the temperature range $370-640 \mathrm{~K}$ are predominantly butene.

the sulfates [46] and the oxygen containing functionalities (butoxy groups) and non bridging oxygen of the polyphosphates chains. Nevertheless the presence of the peak at $534.8 \pm 0.1 \mathrm{eV}$, attributable to a bridging oxygen [47], substantiates the formation of polyphosphate chains. The presence of sulfate and polyphosphate is confirmed by the appearance of the signals at $168.8 \pm 0.2 \mathrm{eV}$ for the $\mathrm{S} 2 \mathrm{p}$ and at $135.6 \mathrm{eV}$ for the P2p (figure 4). The sulfur peak due to the $\mathrm{P}=\mathrm{S}$ group is no longer detectable whereas a small signal at $164.0 \mathrm{eV}$ suggests that the formation of the sulfate might involve the intermediate deposition of elemental sulfur $S^{(0)}$.

Previous research has shown that the thermal decomposition of TBP yields predominantly butene and it was suggested that the TBP decomposes by $\mathrm{C}-\mathrm{O}$ bond scission to give butyl groups on the surface [48]. The decomposition of TBT to butanal suggests that the

Table 5 .

TPRS peak areas for the desorption products of TBP and TBT on Fe and the ionization patterns of butene, butanal, and butanol.

\begin{tabular}{|c|c|c|c|c|c|c|}
\hline Fragment & $m / q$ & $\mathrm{~A}_{1 \text {-butene }}(170-370 \mathrm{~K})$ & $\mathrm{A}_{1 \text {-butanol }}(150-320 \mathrm{~K})$ & $A_{\text {butanal }}(130-340 \mathrm{~K})$ & $\mathrm{A}_{\mathrm{TBP}}(370-640 \mathrm{~K})$ & $\mathrm{A}_{\text {Tвт }}(370-640 \mathrm{~K})$ \\
\hline $\mathrm{C}_{3} \mathrm{H}_{5}{ }^{+}$ & 41 & 100 & 100 & 100 & 100 & 100 \\
\hline $\mathrm{C}_{3} \mathrm{H}_{7}^{+}$ & 43 & 0 & 53 & 99 & 36 & 82 \\
\hline $\mathrm{C}_{3} \mathrm{H}_{8}{ }^{+}$ & 44 & 0 & 30 & 99 & 24 & 74 \\
\hline $\mathrm{C}_{4} \mathrm{H}_{7}^{+}$ & 55 & 14 & 17 & 15 & 12 & 8 \\
\hline $\mathrm{C}_{4} \mathrm{H}_{8}^{+}$ & 56 & 27 & 53 & 17 & 21 & 20 \\
\hline $\mathrm{C}_{4} \mathrm{H}_{9}{ }^{+}$or $\mathrm{C}_{3} \mathrm{H}_{5} \mathrm{O}^{+}$ & 57 & 1 & 7 & 26 & 12 & 21 \\
\hline $\mathrm{C}_{4} \mathrm{H}_{8} \mathrm{O}^{+}$ & 72 & 0 & 2 & 25 & 5 & 20 \\
\hline
\end{tabular}




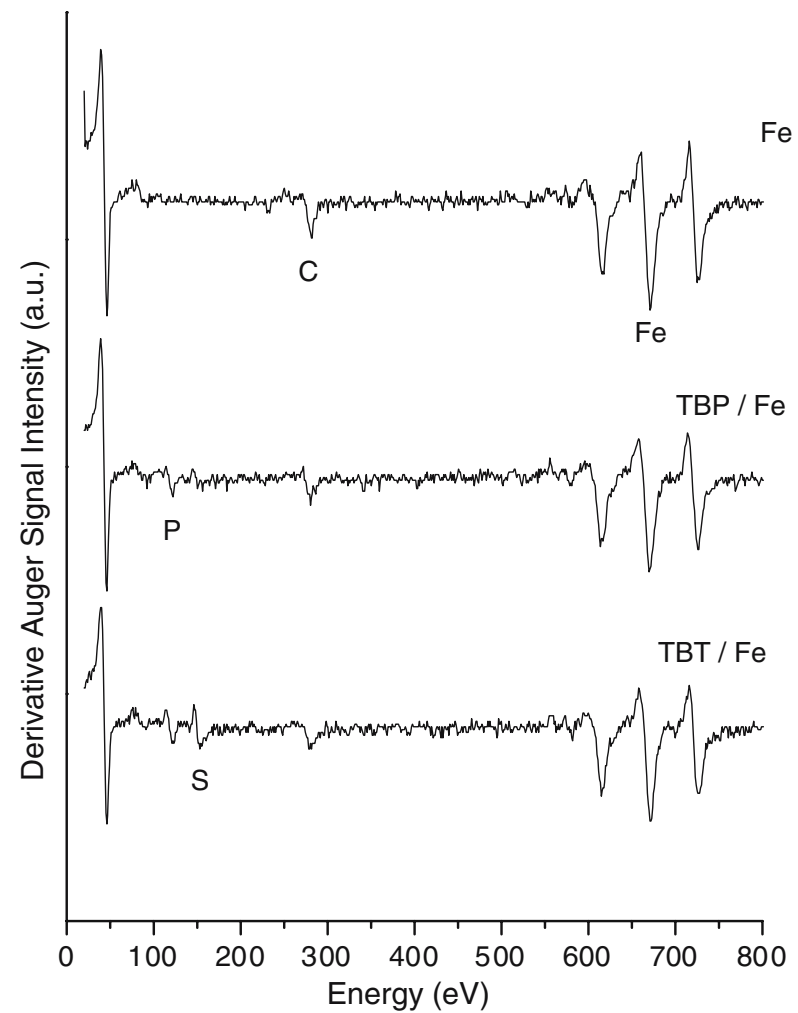

Figure 9. AES spectra of the Fe surface before and after the adsorption and decomposition of TBP and TBT. The sputtered surface still has some carbon and oxygen contamination. After the adsorption and decomposition of TBP there is evidence of the deposition of phosphorus. After the adsorption and decomposition of TBT there is evidence of the deposition of both sulfur and phosphorus.

mechanism involves $\mathrm{P}-\mathrm{O}$ bond scission to give butoxy groups. These then tend to react by $\beta$-hydride elimination to yield butanal. The formation of the butoxy groups from TBT might be preceded by $\mathrm{P}=\mathrm{S}$ bond scission to give tributyl phosphite, which then undergoes $\mathrm{P}-\mathrm{O}$ bond scission to give the butoxy groups. This would be consistent with the surface chemistry of trimethyl phosphite and tributyl phosphite, which decompose to produce alkoxy groups on $\mathrm{Fe}$ [49-51] (scheme 2).

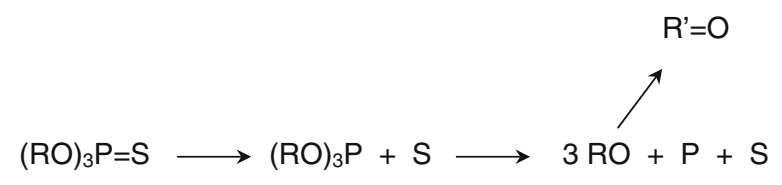

Scheme 2. TBT reaction mechanism on Fe surface.

\subsection{Composition of the tribological film}

The tribological test combined with heating seems to promote the reaction with the oxidized iron surface. The changes detected with ATR-FT-IR spectroscopy following tribological stress (figure 5) are similar to those observed by thermal treatment (figure 3) at $373 \mathrm{~K}$, with the difference that the intensity of the band at $1130 \mathrm{~cm}^{-1}$ is, relative to the band at $1123 \mathrm{~cm}^{-1}$, much higher in the spectrum acquired after tribotesting, and that the band maximum is shifted towards lower wavenumbers. This may suggest the formation of alkyl sulfones, which generally absorb at $1335-1300 \mathrm{~cm}^{-1}$ and 1170 $1130 \mathrm{~cm}^{-1}[43,44]$. On the other hand XPS indicates that the film after tribological stress consists of an organic layer mainly involving species containing carbon bonded to oxygen $(\mathrm{C} 1 \mathrm{~s}$ signal at $286.4 \mathrm{eV})$, and a mixture of iron sulfate and poly(thio)phosphate, as is suggested by the binding energies of the phosphorus, oxygen and iron XPS signals (table 4). The sulfur signal at $164 \mathrm{eV}$ completely disappeared, whereas a new signal at even higher binding energy than that of iron sulfate may suggest the presence of alkyl-S-O groups.

\subsection{Role of sulfur in the surface chemistry of $T B T$}

It has to be emphasized that the presence of sulfur facilitates the chemical and the tribochemical reactions at temperatures of $373 \mathrm{~K}$. At room temperature the molecule is physisorbed. The reaction between TBT and iron occurs very probably via an initial $\mathrm{P}=\mathrm{S}$ bond scission; the presence of sulfur in the molecule lowers the temperature of reaction by around $50 \mathrm{~K}$ compared to the surface reaction of tributylphosphate [33]. Sulfur reacts with iron and mainly forms iron sulfate, whereas the scission of the molecule at the $\mathrm{C}-\mathrm{O}-\mathrm{P}$ bond can explain the formation of the polyphosphates on the iron surface due to the presence of a natural oxide film that might supply the oxygen for the reaction.

The formation of long-chain polyphosphate seems to be facilitated by the presence of sulfur, as has also been suggested in the case of di- and triphenyl phosphates that could react to form long chain polyphosphates when the lubricant oil was blended with sulfurized ester [52]. Glasses with lower $\mathrm{Fe} / \mathrm{P}$ ratios possess longer $\mathrm{P}-\mathrm{O}-\mathrm{P}$ chains [47].

The presence of a component at higher binding energy, $170.5 \mathrm{eV}$, in the sulfur spectra recorded after the tribological test can be assigned to the presence of a sulfur-containing organic compound, in which the $\mathrm{S}$ atom is bonded to oxygen. To support this assignment the Auger parameter (using the S2p and S KLL energies) was calculated and a quite significant change was found: from $2274.4 \pm 0.1 \mathrm{eV}$ for the pure frozen TBT to $2277.0 \pm 0.1 \mathrm{eV}$ for the thermal film at $373 \mathrm{~K}$ and $2276.6 \pm 0.1 \mathrm{eV}$ for the component that appears after the sliding test. These shifts of the Auger parameter are of the same order of magnitude of those reported in Ref. [53] for compounds such as $\left(\mathrm{CH}_{3}\right)_{2} \mathrm{SO}$ and $\left(\mathrm{CH}_{3} \mathrm{O}\right)_{2} \mathrm{SO}$.

\section{Conclusions}

The results presented in this work indicate the formation of iron polyphosphates and sulfate together with 
butanal as the organic product, following thermal decomposition of TBT on iron surfaces. These thermal and the tribochemical reactions do not occur at temperatures below $373 \mathrm{~K}$.

After tribological tests the surface composition is similar to that observed following thermal reaction in a qualitative sense, whereas the amounts of sulfate and polyphosphate are higher following mechanical stress.

The role of sulfur is that of facilitating the reaction-lowering the reaction temperature and favoring the formation of long-chain iron polyphosphates.

\section{Acknowledgments}

The authors would like to thank Dr. H. Camenzind (Ciba Specialty Chemicals, Switzerland) for supplying the purified tributyl thiophosphate and tributyl phosphate, and Mr. M. Horisberger (PSI, Villigen, Switzerland) for preparing the iron coatings by magnetron sputtering. AJG and DK acknowledge support from NSF grant no. CMS0408574.

\section{References}

[1] A.M. Barnes, K.D. Bartle and R.A. Thibon, Tribol. Int. 34 (2001) 389.

[2] A.J. Gellman and N.D. Spencer, J. Eng. Tribol. 216 (2002) 443.

[3] H. Spikes, Tribol. Lett. 17 (2004) 469.

[4] R.J. Bird and G.D. Galvin, Wear 37 (1976) 143.

[5] M. Kasrai, M. Fuller, M. Scaini, Z. Yin, R.W. Brunner, G.M. Bancroft, M.E. Fleet, K. Fyfe and K.H.Tan, Study of Tribochemical Film Formation Using X-ray Absorption and Photoelectron Spectroscopies, Proc. 21st Leeds/Lyon Symposium on Tribology, Lubricants and Lubrication, Sept.1994, D. Dowson et al. eds. (Elsevier Science B:V: 1995), pp. 659-669.

[6] K.L. Rhodes and P.C. Stair, Tribol. Trans. 36 (1993) 27.

[7] M. Eglin, A. Rossi and N. D. Spencer, Tribol. Lett. 15 (2003) 199.

[8] F.M. Piras, A. Rossi and N.D. Spencer, Tribol. Lett. 15 (2003) 181.

[9] R. Schumacher, H. Zinke, D. Landolt and H.J. Matthieu, Wear 146 (1991) 25.

[10] J.M. Martin, C. Grossiord, T. Le Mogne and A. Tonck, Trib. Intern. 34 (2001) 523.

[11] M. Belin, J.M. Martin and J.L. Mansot, Trib. Trans. 32 (1989) 410.

[12] M. Fuller, Z. Yin, M. Kasrai, G.M. Bancroft, E.S. Yamaguchi, P.R. Ryason, P.A. Willermet and K.H. Tan, Trib. Int. 30 (1997) 305.

[13] M.L. Suominen Fuller, M. Kasrai, G.M. Bancroft, K. Fyfe and K.H. Tan, Trib. Int. 31 (1998) 627.

[14] A. Rossi, M. Eglin, F.M. Piras, K. Matsumoto and N.D. Spencer, Wear 256 (2004) 578.

[15] C. Minfray, J.M. Martin, M.I. De Barros, T. Le Mogne, R. Kersting and B. Hagenhoff, Tribol. Lett. 17 (2004) 351.

[16] F.M. Piras, A. Rossi and N.D. Spencer, In-situ attenuated total reflection (ATR), spectroscopic analysis of tribological phenomena, Trib. Ser.40, "Boundary and Mixed Lubrication: Science and Application" (2002), pp. 199-206.

[17] F.M. Piras, A. Rossi and N.D. Spencer, Langmuir 18 (2002) 6606

[18] L.A. Huezo, P.V. Kotvis, C. Crumer, C. Soto and W.T. Tysoe, Appl. Surf. Sci. 78 (1994) 113
[19] D. Glushove-Corby, P.M. Cann and H.A. Spikes, in Tribology 2001, Plenary and Session key papers from the 2nd World Tribology Congress (2001), 333.

[20] N.H. Forster, Tribol. Trans. 42 (1999) 1.

[21] C.S. Saba and N.H. Forster, Tribol. Lett. 12 (2002) 135.

[22] D. Sung and A.J. Gellman, Tribol. Int. 35 (2002) 579.

[23] D. Sung and A.J. Gellman, Tribol. Lett. 13 (2002) 9.

[24] M. Abdelmaksoud, J.W. Bender and J. Krim, Tribol. Lett. 13 (2002) 179.

[25] M. Abdelmaksoud, J.W.Bender and J. Krim, Physical Review Letters 92 (2004) 176101-1-176101-4.

[26] F. Gao, P.V. Kotvis, D. Stacchiola and W.T. Tysoe, Tribol. Lett. 18 (2005) 377.

[27] D.X. Ren, D.Y. Sung and A.J. Gellman, Tribol. Lett. 10 (2001) 179.

[28] M.N. Najman, M Kasrai, G.M. Bancroft and R. Davidson, Tribol. Int. 39 (2006) 342.

[29] Z. Zhang, E.S. Yamaguchi, M. Kasrai, G.M. Bancroft and M.N. Najman, Tribol. Lett. 19 (2005) 211.

[30] M.N. Najman, M. Kasrai, G.M. Bancroft, B.H. Frazer and G. De Stasio, Tribol. Lett. 17 (2004) 811.

[31] M.N. Najman, M. Kasrai and G.M. Bancroft, Tribol. Lett. 17 (2004) 217.

[32] Q. Y. Gong, W.R. He and W.M. Liu, Tribol. Int. 36 (2003) 733.

[33] F.M. Piras, In Situ Attenuated total reflection tribometry. A new approach for the chemical analysis of tribological films, Ph.D. thesis ETH No. 14638 (2002).

[34] ISO 15472:2001, Surface Chemical Analysis - X-ray Photoelectron Spectrometers - Calibration of energy scales.

[35] J. H. Scofield, J. Electron Spectrosc. Relat. Phenom. 8 (1976) 129.

[36] K. Berresheim, M. Matternklosson and M. Wilmers, Fresenius J. Anal. Chem. 341 (1991) 121.

[37] M. P. Seah and W. A. Dench, Surf. Interface Anal. 1 (1979) 2.

[38] K. Moedritzer and R.R. Irani, J. Inorg. Nucl. Chem. 22 (1961) 297.

[39] D. Lin-Vien, N.B. Colthup, W.G. Fateley and J.G. Grasselli, The Handbook of Infrared and Raman Characteristic Frequencies of Organic Molecules, Ch. 16 (Academic Press Inc., 1991).

[40] L.C. Thomas and R.A. Chittenden, Spectrochim. Acta 20 (1964) 489.

[41] J.R. Ferraro, D.F. Peppard and G.W. Mason, Spectrochim. Acta 19 (1963) 811.

[42] R.R. Shagidullin, A.V. Chernova, V.S. Vinogradova and F.S. Mukhametov, Atlas of IR Spectra of Organophosphorus Compounds (Kluwer Academic Publishers, 1990).

[43] L.J. Bellamy, The Infrared Spectra of complex molecules, Vol. 2 (Chapman and Hall, 1980) pp. 221-226.

[44] J. Coates, in Interpretation of Infrared spectra A practical approach, Encyclopedia of Analytical Chemistry, R.A. Meyers ed. (John Wiley \& Sons, 2000) 14.

[45] M. Eglin, A. Rossi, F.M. Piras, N.D. Spencer, in Surface Science Spectra, Vol. 8 (American Chemical Society, 2002) pp. 97.

[46] K. Matsumoto, ETH-Zürich, Dissertation No. 15150, 2003.

[47] R. Pinna, Synthesis, XPS and ToF-SIMS characterization of zinc and iron polyphosphates glasses, Diploma thesis (University of Cagliari, Italy, 2002).

[48] D. Sung and A.J. Gellman, Trib. Int. 35(9)(2002) 579.

[49] F. Gao, O. Furlong, P.V. Kotvis and W.T. Tysoe, Langmuir 20 (2004) 7557.

[50] D. Ren and A.J. Gellman, Trib. Int. 34 (2001) 353.

[51] A.W. Holbert, J.D. Batteas, A. Wong-Foy, T.S. Rufael and C.M. Friend, Surf. Sci. 401 (1998) L437.

[52] M.N. Najman, M. Kasrai and G.M. Bancroft, Wear 257 (2004) 32.

[53] R.N.S. Sodhi and R.G. Cavell, J. Electron Spectrosc. 41 (1986) 1. 